\title{
The Choice of Environmental Policy Instruments: Energy Efficiency and Redistribution
}

\author{
Alexander Haupt \\ Magdalena Stadejek
}

\author{
CESIFO WORKING PAPER NO. 2986 \\ CATEGORY 9: RESOURCE AND ENVIRONMENT ECONOMICS \\ MARCH 2010
}

Presented at CESifo Area Conference on Energy \& Climate Economics, OCtober 2009

\footnotetext{
An electronic version of the paper may be downloaded

- from the SSRN website:

- from the RePEc website:

www.SSRN.com

WwW.RePEc.org

- from the CESifo website:

www.CESifo-group.org/wp
} 


\title{
The Choice of Environmental Policy Instruments: Energy Efficiency and Redistribution
}

\begin{abstract}
We analyse optimal environmental policies in a market that is vertically differentiated in terms of the energy efficiency of products. Considering energy taxes, subsidies to firms for investment in more eco-friendly products, and product standards, we are particularly interested in how distributional goals in addition to environmental goals shape the choice of policy instruments. Surprisingly, we find that an industry-friendly government levies an energy tax to supplement a lax product standard, but shies away from subsidies to firms. By contrast, a consumer-friendly government relies heavily on a strict product standard and in addition implements a moderate subsidy to firms, but avoids energy taxes.
\end{abstract}

JEL-Code: Q58, Q48, L13, L15, L50.

Keywords: energy tax, energy efficiency standard, subsidy, vertically differentiated markets, product quality.

\author{
Alexander Haupt \\ Plymouth Business School \\ University of Plymouth \\ Drake Circus \\ UK - Plymouth, PL4 8AA \\ alexander.haupt@plymouth.ac.uk
}

\author{
Magdalena Stadejek \\ Department of Economics \\ European University Viadrina \\ P.O. Box 1786 \\ Germany - 15207 Frankfurt (Oder) \\ stadejek@euv-frankfurt-o.de
}

\section{March 2010}

We thank participants at the CESifo Area Conference on Energy and Climate Economics in Munich and a research seminar at the European University Viadrina, particularly Cathrine Hagem and Wolfgang Peters, for their valuable comments. A. Haupt gratefully acknowledges financial support from CESifo. M. Stadejek thanks the state of Brandenburg for her scholarship. 


\section{Motivation}

The continuing deterioration of the environment is one of the major political challenges. Broadly speaking, we can lower our negative impact on the environment by reducing overall consumption or by cutting the environmental damage per consumption unit. Policies that try to curb household consumption, however, will not always be successful. Many consumption activities, such as using washing machines, refrigerators, computers, TV sets and vehicles are highly price inelastic. Households will not easily give up washing their clothes, even when they face higher energy or water prices. And rising fuel prices may only marginally affect individual driving habits. In many areas, a more promising government strategy is to aim at reducing the environmental damage per consumption unit, for instance, by promoting more energy and water efficient washing machines.

Energy and water efficiency gains have indeed significantly contributed to limiting the negative impact of consumption activities on the environment. In the EU, the average energy consumption of washing machines per $\mathrm{kg}$ of capacity decreased by $37 \%$ between 1992 and 2005, and average water consumption went down by $31 \%$ between 1997 and 2005 (Faberi et al., 2007). In the US, refrigerators consumed, on average, in 2001 only $25 \%$ of the energy used in 1972. Compared to the hypothetical energy consumption at the old level of efficiency, this improvement saves the US 200 billion $\mathrm{kWh}$, which is about the annual energy consumption of California (Rosenfeld et al., 2004). ${ }^{1}$

Thus, in this paper, we focus on environmental policy as a means to improving energy efficiency (or likewise water efficiency). Considering energy taxes, subsidies for investments in more eco-friendly products, and energy efficiency standards, we are particularly interested in how distributional goals in addition to environmental goals shape the choice of policy instruments. Surprisingly, we find that an industryfriendly government levies an energy tax to supplement a lax efficiency standard, but shies away from subsidies to firms. By contrast, a consumer-friendly government heavily relies on a strict efficiency standard and additionally implements a subsidy to firms, but avoids energy taxes.

We derive these results in a model with vertical product differentiation. Two firms first invest in the energy efficiency of their products and then are engaged in price competition. Households buy one of the products and complementary energy. They differ in the intensity with which they use these goods, and thus in their need for energy, which is produced in a separate sector. The government can implement

\footnotetext{
${ }^{1}$ Further improvements are possible even with today's technologies. For instance, Fraunhofer IZM (2007) estimates that the average on-mode energy consumption of a 32 " LCD TV set can be reduced by $15 \%$ to $30 \%$, simply by applying available technologies.
} 
an energy tax, a subsidy or a standard, and might be biased towards industry or consumers. It balances its budget by taxes on or transfers to households.

As is well known, each firm invests in a product with a distinct level of quality, here in terms of energy efficiency, to differentiate itself from its competitor and thus weaken price competition. ${ }^{2}$ As a consequence of imperfect competition, the government must employ two instruments to achieve optimal energy efficiency levels of both high quality and low quality products. First, it needs a subsidy to firms or an energy tax to induce the high quality firm to improve its product's energy efficiency. Second, the government has to additionally implement a minimum energy efficiency standard for energy using products, since the low quality firm is insensitive to pecuniary incentives.

Distributional preferences matter when it comes to the extent to which different instruments are used. An industry-friendly government relies heavily on an energy tax, as such a tax increases the energy cost differential between the products of the two firms. An energy tax thus accentuates the quality differential between the products, thereby weakening price competition and ultimately increasing the profits of the two firms. Also, an industry-friendly government introduces only a lax minimum energy efficiency standard. The reason is that such a standard narrows the quality gap between the products, thereby reinforcing price competition and thus reducing profits.

In contrast, a consumer-friendly government imposes a strict standard and grants a subsidy that covers a share of each firm's investment in a more energy efficient product. From the perspective of households, such a subsidy increases energy efficiency at lower cost to consumers than an energy tax, even though the subsidy will be financed by households and the tax revenues will be given back to households. In contrast to an energy tax, however, a subsidy does not directly weaken price competition between firms and thus keeps product prices down.

Our paper shows that the distributional consequences of environmental policy can be counter-intuitive. At first glance, it is surprising that the industry gains more from an energy tax than from a direct subsidy. Likewise, it is far from obvious that households benefit more from paying for subsidies to firms than from implementing an energy tax, given that tax revenues are handed back to households. Moreover, our paper provides a justification for a sensible use of command-and-control instruments as a supplement to market-based instruments. Independent of the government's distributional preferences, product standards are somewhat necessary in addition to

\footnotetext{
${ }^{2}$ Seminal papers on vertically differentiated markets include, for example, Gabszewicz and Thisse (1979), Shaked and Sutton (1982), Cremer and Thisse (1994), and Crampes and Hollander (1995). These contributions, however, do not consider environmental issues.
} 
taxes or subsidies.

Several previous papers have applied models with vertically differentiated markets to environmental problems. Our paper has three key features that set it apart from these contributions. First, we analyse the optimal choice of environmental policy instruments. In particular, we show how the distributional preferences of the government determine which instruments are chosen and to what extent the chosen instruments are applied. Our analysis is important because most policy decisions are indeed at least partly driven by concerns about distribution, and not merely by efficiency considerations. For a variety of reasons, governments carry out redistributive measures not only directly but also indirectly, and in basically all policy areas, including environmental policy. In contrast to our contribution, many previous papers explore the impact of exogenous policy changes without considering the optimal policy and choice of instruments (e.g. Arora and Gangopadhyay, 1995; Bansal and Gangopadhyay, 2003; Moraga-González and Padrón-Fumero, 2002; Ronnen, 1991) or ignore distributional preferences of the government (e.g. Bansal, 2008; Lombardini-Riipinen, 2005).

Second, we focus on the joint consumption of vertically differentiated goods and energy. Our approach enables us to analyse the impacts of an energy tax in addition to those of an energy efficiency standard and a direct subsidy to firms. A major characteristic of an energy tax is that it affects the 'consumption costs' of different households consuming the very same product very differently, depending on the intensity with which households use the specific product. And indeed, this 'differentiated' impact of an energy tax on 'consumption costs' is exactly the reason why this instrument so effectively curbs price competition and turns out to be so attractive to an industry-friendly government. In contrast, previously analysed taxes in models with differentiated products, such as ad valorem taxes on goods and taxes on emissions generated in the production process (e.g. Bansal, 2008; Cremer and Thisse, 1999; Lombardini-Riipinen, 2005), lack this particular feature.

Third, households buy eco-friendly goods in our framework because it pays for them in terms of lower energy costs. Our results do not rely on altruistic or 'green' sentiments. By contrast, previous contributions refer to 'green' preferences of consumers (e.g. Eriksson, 2004; Rodriguez-Ibeas, 2007; and papers referred to above) and ignore the role of energy taxes, and likewise water charges.

Our paper is organized as follows. In section 2, we present our model. Section 3 explores the quality and price competition between the firms. We then analyse the optimal environmental policy in section 4. In particular, we show how the choice of instruments and the extent to which these instruments are applied depend on the government's distributional preferences. Section 5 discusses two alternative policy 
instruments and sketches two extensions of the model. Finally, section 6 contains some concluding remarks.

\section{Firms, Households, and the Government}

Two firms compete in a vertically differentiated market, with products distinguished by their energy efficiency. Households differ in the intensity with which they use these products, and thus in the need for complementary energy consumption. Finally, the government can implement an energy tax, a subsidy and a minimum energy efficiency standard to combat a negative environmental externality.

Firms and Technology There are two firms, $H$ and $L$, located in one country. They produce output $y_{i}, i=H, L$. For simplicity, there are no production costs. ${ }^{3}$ The goods can be used with different intensities $z$, and their consumption requires a complementary energy consumption $\left(\bar{e}-e_{i}\right)$ per intensity unit. For example, each washing machine can be used once or ten times a week, and each washing cycle needs a machine-specific amount of energy.

While the intensity $z$ depends on household type, the energy consumption $\left(\bar{e}-e_{i}\right)$ per intensity unit is determined by the firms. To reduce energy consumption below the exogenously given basic level $\bar{e}$, firms have to redesign their old products and invent new products with an improved energy efficiency $e_{i} \cdot{ }^{4}$ These inventive activities increase fixed costs $a_{i}$. A threefold continuously differentiable function $a_{i}\left(e_{i}\right)$ captures this notion. It is assumed to fulfil the properties (i) $a_{i}(0)=0$, (ii) $\partial a_{i}(0) / \partial e_{i}=0$ and $\partial a_{i}(\bar{e}) / \partial e_{i}=\infty$, and (iii) $\partial^{2} a_{i} / \partial e_{i}^{2}>0$. These properties guarantee 'well-behaved' fixed costs. In particular, they imply that the higher the energy-efficiency $e_{i}$ already is, the more expensive a further increase in $e_{i}$. The resulting fixed costs, however, might be subsidised by the government with rate $s$, yielding private fixed costs $(1-s) a_{i}$.

Without loss of generality, we assume that firm $H(L)$ produces a more (less) energy efficient good, i.e. $e_{H}>e_{L}$. Each firm chooses energy efficiency $e_{i}$ and price

\footnotetext{
${ }^{3}$ We find this assumption in many papers. See, for instance, Arora and Gangopadhyay (1995); Bansal and Gangopadhyay (2003); and Moraga-González and Padrón-Fumero (2002). Energy efficiency can indeed be frequently enhanced without affecting production costs. Fraunhofer IZM (2007), for instance, analyses several available technologies that reduce energy consumption of TV sets cost-neutrally.

${ }^{4}$ Typically, energy efficiency is defined as energy services generated per unit of energy input (Gillingham et al., 2009). In the current framework with constant energy input per service unit of $z$, this would mean that energy efficiency is simply $1 /\left(\bar{e}-e_{i}\right)$. For notational convenience, however, energy efficiency refers to $e_{i}$ in our paper.
} 
$p_{i}$ for its product such that its profit $\pi_{i}=p_{i} y_{i}-(1-s) a_{i}$ is maximised. It thereby takes the decisions of its rival as given.

Households Each household purchases exactly one good, either from firm $H$ or $L$. Households differ in their exogenous consumption intensities $z$. For instance, all households buy a washing machine, but while families use their machines very frequently, singles use theirs far less often. The distribution of the household characteristic $z$ over the interval $[\underline{z}, \bar{z}], \bar{z}>\underline{z}>0$, is captured by a twice-continuously differentiable distribution function $F(z)$ with the properties: (i) $F(\underline{z})=0$ and $F(\bar{z})=1$, (ii) $F^{\prime}(z)>0$, (iii) $\underline{z} F^{\prime}(\underline{z})<1$, and (iv) $F^{\prime \prime}(z) \in$ $\left(-2\left(F^{\prime}(z)\right)^{2} /(1-F(z)), 2\left(F^{\prime}(z)\right)^{2} / F(z)\right)$. The first two properties are obvious. The last two properties guarantee well-behaved profit functions.

Denoting by $t$ the gross price of energy (including energy tax), household $h$ 's total costs of consuming good $y_{i}$ with intensity $z_{h}$ amount to $p_{i}+t\left(\bar{e}-e_{i}\right) z_{h}$. Each household then chooses the good - either $H$ or $L$ - that minimises its total consumption costs. Equivalently, we can say that each household maximises its 'residual' income $m_{h}=x-p_{i}-t\left(\bar{e}-e_{i}\right) z_{h}+b$, given that it consumes one unit of good $y_{i}$ with intensity $z_{h}$. Here, the variable $x$ stands for a household's gross income and the variable $b$ for the lump-sum transfer from, or tax to, the government. We assume that income $x$ is sufficiently high to pay a possible tax and for one of the products and a household's need for energy. Finally, we normalise the number of households to one.

Energy and the Environment Profit-maximising firms in a competitive sector generate energy at constant marginal $\operatorname{costs} c$. Perfect competition implies that the net energy price households have to pay (i.e. excluding energy tax) equals marginal $\operatorname{costs} c$. Adding up individual energy consumption $\left(\bar{e}-e_{i}\right) z_{h}$ yields aggregate energy consumption $E$, which in turn causes environmental damage $D(E)$. This threefold continuously differentiable function expresses damage in pecuniary terms. It is, as usual, assumed to be convex, i.e. $\partial D / \partial E>0$ and $\partial^{2} D / \partial E^{2} \geq 0$ hold.

Government The government has three policy instruments at its disposal, an energy tax rate $\tau \geq 0$, a subsidy rate $s \in[0,1)$ and a minimum energy efficiency standard $e_{\text {min }}$. This standard $e_{\text {min }}$ defines the minimum energy efficiency $e_{i}$ that products have to achieve. It is limited to $e_{l i m}$, i.e. $e_{\min } \leq e_{l i m}$. The limit $e_{l i m}$ is sufficiently low so that both firms ultimately stay in business; that is, each of them makes a non-negative profit. ${ }^{5}$ In this sense, we only allow non-drastic standards.

\footnotetext{
${ }^{5}$ Similarly, Arora and Gangopadhyay (1995), Moraga-González and Padrón-Fumero (2002) and Ronnen (1991), among others, focus on minimum standards that allow two firms to stay in the
} 
This constraint reflects the fact that 'historical' production rights and legal fidelity apart from political-economic reasons - prevent the government from implementing drastic regulations that would drive firms out of the market. Finally, the government uses the tax revenues for lump-sum transfers to households, or levies a lump-sum tax on households to finance the subsidy to the firms.

The government aims at maximising the weighted aggregate welfare

$$
W=\alpha \underbrace{\left(\pi_{H}+\pi_{L}\right)}_{\text {Industry welfare }}+\underbrace{[M-D(E)]}_{\text {Consumer welfare }} \text { s.t. } \tau c E=b+s\left(a_{H}+a_{L}\right) .
$$

The government's objective (1) can be decomposed into consumer welfare, which consists of aggregate 'residual' income $M$ net of environmental damage $D(E)$, and industry welfare, which is equal to aggregate profits $\pi_{H}+\pi_{L}$. The parameter $\alpha$, which assigns a weight to industry profits, is given exogenously. We refer to a government with $\alpha>1(\alpha<1)$ as industry-friendly (consumer-friendly). The borderline case $\alpha=1$ constitutes our benchmark. In this case, we label the government as neutral. We restrict the possible values of $\alpha$ to the interval $[\underline{\alpha}, \bar{\alpha}]$, where $\underline{\alpha}<1<\bar{\alpha}$ and $\underline{\alpha}$ and $\bar{\alpha}$ are sufficiently close to one to guarantee a well-behaved welfare function. As usual, tax revenues $\tau c E$ have to balance government spending, consisting of subsidy payments $s\left(a_{H}+a_{L}\right)$ and a lump-sum transfer $b$ to households (which might be negative, i.e. a lump-sum tax).

Timing Decisions take place in three stages. In the first stage, the government sets energy tax rate $\tau$, subsidy rate $s$, and energy efficiency standard $e_{\min }$. In the second stage, the two non-cooperative firms decide simultaneously on the energy efficiency of their goods, $e_{H}$ and $e_{L}$. In the third stage, the firms choose again simultaneously their prices, $p_{H}$ and $p_{L}$. Households decide which product they purchase, and buy the corresponding amount of energy.

Remarks Some of our assumptions diverge from those in related models and may need some additional discussions. Our first remark concerns the consumption patterns of households. We follow the line of reasoning in several papers on vertically differentiated markets in assuming that each household consumes exactly one unit of one of the two product types. ${ }^{6}$ In contrast to the literature, however, we additionally assume that households differ in the intensity with which these goods are used. As the above example of washing machines particularly illustrates, we focus market.

${ }^{6}$ The assumption that the market is fully covered is widespread in the literature. Examples are Bansal (2008), Crampes and Hollander (1995), Cremer and Thisse (1994, 1999) and Eriksson (2004). 
on goods that can be found in (almost) every household, but are used with different intensities. These goods include - besides washing machines - television sets, refrigerators, computers, vehicles, and so on.

The demand for these goods, and even the intensity of their use, is rather fixed, or at least highly price-inelastic. Whether households wash their dirty clothes, watch the news, check their emails, and so on is hardly affected by energy prices. And even our driving behaviour is fairly insensitive to fuel prices. Instead, consumption intensities are determined to a large degree by household characteristics - such as household size - and price-inelastic consumer habits - such as preferring car to train journeys. When purchasing a washing machine and the like, however, households are aware of their intensity of use and the implication for their energy consumption, and accordingly choose their products. ${ }^{7}$ They are more inclined to buy an energy efficient but expensive washing machine, the more often they will use it, and thus the more energy costs they will save.

Consequently, aiming at more energy efficient products is an important pillar of environmental policy. This aspect is stressed in our basic framework. We focus on endogenous household product choices and the impact of environmental policy on these choices, taking total demand and consumption intensity as given. In section 5 , however, we sketch an extension to the model that allows for endogenously determined consumption intensities. There, we argue that our results are robust with respect to this modification under reasonable assumptions, and provide empirical support for our assumptions.

Related to this issue is the next point. Since demand and consumption intensity are considered to be exogenous, we can omit the associated household utility without affecting our results. Instead, individual consumer welfare is simply measured by residual income $m_{h}$ net of environmental damage.

The government's objective function, which assigns the weight $\alpha$ to industry profits, might reflect the politicians 'intrinsic' distributional preferences. Alternatively, it can be interpreted as a political support function. Then, the weight $\alpha$ stands for the industry's political influence - for instance, for its ability to lobby effectively. This kind of political support function can be derived from more sophisticated models of public decision making. For our purpose, however, this reduced form is sufficient, since we are predominantly interested in the implications of 'biased' government choices for environmental policies, not in its causes. ${ }^{8}$

\footnotetext{
${ }^{7}$ Importantly, consumers can nowadays easily collect and compare information about the products' energy efficiency. In the EU, for instance, manufacturers of household appliances are required to provide information about their products' energy efficiency, and retailers have to clearly label this information. See Council of the European Communities (1992).

${ }^{8}$ See Peltzman (1976) for a seminal paper on political support functions and Rauscher (1997),
} 
Finally, note that we refer to energy efficiency and an energy tax. The same line of reasoning, however, would of course be valid for water efficiency and a water charge.

\section{Market Equilibrium}

As usual, we solve our model by backward induction and look for the subgameperfect equilibrium. In this section, the market outcome is analysed for a given environmental policy.

\subsection{Price Competition}

In the third stage, each household $h$ decides on whether one unit of either product $y_{H}$ or product $y_{L}$ is purchased. The corresponding total consumption costs are either $p_{H}+t\left(\bar{e}-e_{H}\right) z_{h}$ or $p_{L}+t\left(\bar{e}-e_{L}\right) z_{h}$, where $t=(1+\tau) c$. Comparing the two values reveals that a household prefers good $H(L)$ if and only if its consumption intensity $z_{h}$ is above (strictly below) the threshold value

$$
\widetilde{z}=\frac{p_{H}-p_{L}}{(1+\tau) c\left(e_{H}-e_{L}\right)} .
$$

This threshold level is determined by the ratio of the price differential $p_{H}-p_{L}$ to energy cost differential $(1+\tau) c\left(e_{H}-e_{L}\right)$. Obviously, all households would go for the more energy efficient product if its price $p_{H}$ were equal or lower than its rival's price $p_{L}$. (We exclude the case $e_{H}=e_{L}$, since this can never be a subgameperfect equilibrium, as discussed below.) For $p_{H}>p_{L}$, only households with a high consumption intensity $z_{h} \geq \widetilde{z}$ purchase the more energy efficient good, since their savings in energy costs more than compensate them for the higher product price. The other households prefer the less energy efficient good, since the lower product price more than offsets their higher energy costs.

Consequently, the two demand functions for goods $H$ and $L$ are $y_{H}=1-F(\widetilde{z})$ and $y_{L}=F(\widetilde{z})$, respectively. Then the profits of the two firms are

$$
\pi_{H}=p_{H}[1-F(\widetilde{z})]-(1-s) a_{H} \quad \text { and } \quad \pi_{L}=p_{L} F(\widetilde{z})-(1-s) a_{L}
$$

At this stage, the energy efficiency levels $e_{H}$ and $e_{L}$ are given, and the corresponding fixed $\operatorname{costs} a_{H}$ and $a_{L}$ are sunk. Also, the energy tax rate $\tau$ is already determined, and the net energy price is equal to $c$ (which follows from constant marginal costs $c$ of energy generation and perfect competition in the energy sector). Then, each firm

chapter 7 , for an application to environmental issues. 
maximises its profit (3) with respect to its price, taking the choice of its competitor as given. This maximisation implies the usual trade-off. A higher price reduces demand, but increases the revenues from the remaining customers. Firms balance these two opposing effects, and rearranging the first order conditions for an interior solution implicitly yields the prices ${ }^{9}$

$$
p_{H}=(1+\tau) c\left(e_{H}-e_{L}\right) \frac{1-F(\widetilde{z})}{F^{\prime}(\widetilde{z})} \text { and } \quad p_{L}=(1+\tau) c\left(e_{H}-e_{L}\right) \frac{F(\widetilde{z})}{F^{\prime}(\widetilde{z})} .
$$

Calculating the price differential $p_{H}-p_{L}$ and inserting the resulting expression into the threshold condition (2) then leads to the equilibrium threshold level

$$
\widetilde{z}=\frac{1-2 F(\widetilde{z})}{F^{\prime}(\widetilde{z})} \text {. }
$$

Assuming that $e_{H}>e_{L}$ holds, we can now characterise the price competition equilibrium.

\section{Lemma 1 Price Competition}

(i) A unique price competition equilibrium $\left(p_{H}, p_{L}, \widetilde{z}\right)$ exists. Both prices are positive and given by (4), with $p_{H}>p_{L}$. Threshold $\widetilde{z}$ lies in the open interval $(\underline{z}, \bar{z})$ and is given by (5).

(ii) Threshold $\widetilde{z}$ and the resulting positive output levels $y_{H}=1-F(\widetilde{z})$ and $y_{L}=F(\widetilde{z})$ are independent of energy tax rate $\tau$ and energy efficiency levels $e_{H}$ and $e_{L}$.

(ii) Both prices, $p_{H}$ and $p_{L}$, increase (decrease) with energy efficiency $e_{H}\left(e_{L}\right)$. That is, $\partial p_{i} / \partial e_{H}>0$ and $\partial p_{i} / \partial e_{L}<0$. More importantly, both prices, $p_{H}$ and $p_{L}$, increase with energy tax rate $\tau$. That is, $\partial p_{i} / \partial \tau>0$.

Proof. See appendix.

The intuition behind these results is straightforward. A more energy efficient good $H$ widens the quality gap. Since the products then become more differentiated, price competition is weakened, and both firms raise their prices. By contrast, a higher energy efficiency of good $L$ narrows the quality gap, yielding less differentiated products. Consequently, price competition is intensified, and both firms lower their prices. $^{10}$ No matter whether quality $e_{H}$ or $e_{L}$ varies, the price differential $p_{H}-$ $p_{L}$ increases, or decreases, proportionally to the quality gap $e_{H}-e_{L}$, leaving the threshold $\widetilde{z}$ and equilibrium demand for each good unchanged.

More interestingly, a higher tax allows both firms to raise their prices. The reason is that a higher tax increases the energy cost differential $(1+\tau) c\left(e_{H}-e_{L}\right)$, thus

\footnotetext{
${ }^{9}$ The second order condition for profit maximisation is satisfied for both firms under property (iv) of the distribution function.

${ }^{10}$ This kind of result is well known from the literature on vertically differentiated markets. See, for instance, Ronnen (1991).
} 
generating more economically differentiated goods $H$ and $L$. Since greater economic differentiation alleviates price competition, both firms increase their prices. By contrast, a lower energy tax implies less economically differentiated goods, leading to intensified price competition. Consequently, both firms decrease their product prices.

\subsection{Energy Efficiency Competition}

In the second stage, the two firms determine their products' energy efficiency levels $e_{H}$ and $e_{L}$. Each firm again takes the decision of its competitor and the implemented environmental policy as given. Moreover, it anticipates the impact of its choice of quality on the outcome of the succeeding price competition stage. Taking optimal prices (4) and lemma 1 (ii) into account, the marginal effects of the products' energy efficiency levels on the firms' profits are

$$
\begin{aligned}
\frac{\partial \pi_{H}}{\partial e_{H}} & =(1+\tau) c \frac{[1-F(\widetilde{z})]^{2}}{F^{\prime}(\widetilde{z})}-(1-s) \frac{\partial a_{H}}{\partial e_{H}} \text { and } \\
\frac{\partial \pi_{L}}{\partial e_{L}} & =-(1+\tau) c \frac{[F(\widetilde{z})]^{2}}{F^{\prime}(\widetilde{z})}-(1-s) \frac{\partial a_{L}}{\partial e_{L}}
\end{aligned}
$$

for firm $H$ and firm $L$, respectively. Consider first the situation of the high quality firm $H$ (see (6)). On the one hand, a greater energy efficiency $e_{H}$ widens the quality gap between the products and thus softens price competition. Consequently, prices, revenues and profits increase, as captured by the first term on the RHS. On the other hand, a greater energy efficiency goes along with greater fixed costs, as shown by the second term on the RHS. Since this effect depresses profits, firm $H$ has to balance two opposing effects. The profit-maximising energy efficiency is thus characterised by the first order condition ${ }^{11}$

$$
\frac{\partial a_{H}}{\partial e_{H}}=\frac{(1+\tau)}{(1-s)} \frac{c[1-F(\widetilde{z})]^{2}}{F^{\prime}(\widetilde{z})} .
$$

The situation of the low quality firm $L$ is slightly different (see (7)). A greater energy efficiency $e_{L}$ obviously means higher fixed costs, as in the case of its competitor. This effect is again captured by the second term on the RHS. In addition, a greater energy efficiency closes the quality gap, and thus reinforces price competition. In response, prices, revenues and profits decline, as reflected in the first term on the RHS. Since both effects work into the same direction, firm $L$ chooses the lowest possible energy efficiency level, given the environmental standard $e_{\min }$. That is,

$$
e_{L}=e_{\min }
$$

\footnotetext{
${ }^{11}$ The second order condition $\partial^{2} \pi_{H} / \partial e_{H}^{2}=-(1-s) \partial^{2} a_{H} / \partial e_{H}^{2}<0$ is fulfilled.
} 
For sufficiently small $e_{m i n}$, both firms can make non-negative profits, and the resulting quality competition equilibrium is characterised in

\section{Lemma 2 Energy Efficiency Competition}

(i) Up to the permutation of the two firms across the two indices, there exists a unique energy efficiency competition equilibrium $\left(e_{H}, e_{L}\right)$, with $e_{H}>e_{L}=e_{m i n}$ and energy efficiency $e_{H}$ given by (8).

(ii) Energy efficiency $e_{H}$ strictly increases with energy tax rate $\tau$ and subsidy rate $s$ (i.e. $d e_{H} / d \tau>0$ and $d e_{H} / d s>0$ ). It does not respond to changes in standard $e_{\text {min }}$. (ii) Energy efficiency $e_{L}$ strictly increases with energy efficiency standard $e_{\text {min }}$ (more precisely, de $\left.e_{L} / d e_{\min }=1\right)$. It is independent of energy tax $\tau$ and subsidy $s$.

Proof. See appendix.

The arguments behind lemma 2 run as follow. Firms use energy efficiency as a means of vertically differentiating their goods from those of their rivals. A larger energy cost differential $(1+\tau) c\left(e_{H}-e_{L}\right)$ between the products of the two firms weakens price competition and allows both firms to charge higher prices. The marginal impact of a rise in the physical quality gap $e_{H}-e_{L}$ on the energy cost differential, and thus on prices, is the greater, the higher the energy tax $\tau$. In this sense, the energy tax reinforces the importance of the physical quality gap. Consequently, a higher tax increases the incentives to widen the quality gap. The more eco-friendly firm $H$ invests even more in increasing energy efficiency $e_{H}$ while firm $L$ sticks to the lowest possible level of quality $e_{L}$.

In contrast to the energy tax, the subsidy provides a direct incentive to invest more in a product's energy efficiency by lowering a firm's fixed costs. This positive effect, however, only induces the high quality firm to improve the energy efficiency of its product. As a subsidy cannot sufficiently alter the benefits of vertical product differentiation, it cannot affect firm $L$ 's quality decision (as long as the subsidy rate is below one).

The low quality firm only responds to a more strict efficiency standard $e_{\min }$ and adjusts its product's energy efficiency $e_{L}$ accordingly. This measure, however, does not affect the decision of the high quality firm in the second stage. Instead of changing the quality of its product, firm $H$ cuts its prices in the third stage in response to a higher energy efficiency of its rival's product.

The choices of firms and households in the second and third stages lead to the equilibrium energy consumption

$$
E=\left(\bar{e}-e_{L}\right) Z_{L}^{a g g}+\left(\bar{e}-e_{H}\right) Z_{H}^{a g g},
$$

where $Z_{L}^{a g g}=\int_{\underline{z}}^{\widetilde{z}} z F^{\prime}(z) d z$ and $Z_{H}^{a g g}=\int_{\widetilde{z}}^{\bar{z}} z F^{\prime}(z) d z$. 


\section{Environmental Policy}

In the first stage, the government chooses the policy that maximises its objective function subject to its budget constraint. It anticipates the impact of its decision on market equilibrium and environmental damage.

\subsection{Welfare}

Since the government gives tax revenues back to households in a lump-sum fashion, energy tax payments have no direct impact on aggregate residual income $M$. The net tax burden of the households only results from subsidy payments to firms. Thus aggregate residual income $M$ is equal to $x-p_{H} y_{H}-p_{L} y_{L}-c E-s\left(a_{H}+a_{L}\right)$. Then reformulating welfare (1) yields

$$
W=\underbrace{(\alpha-1)\left(\pi_{H}+\pi_{L}\right)}_{\text {Industrial component }}+\underbrace{\left[x-c E-D(E)-a_{H}-a_{L}\right]}_{\text {Traditional component }},
$$

where $\pi_{H}, \pi_{L}, a_{H} a_{L}$, and $E$ are defined by (3), (4), (5), (8), (9), and (10). That is, welfare can be decomposed into a traditional component and an industrial one. The traditional component is simply equal to the sum of consumer welfare $M-D(E)$ and firms' profits $\pi_{H}+\pi_{L}$. The industrial component contains the firms' profits $\pi_{H}+\pi_{L}$, revalued by the 'net' weight $(\alpha-1)$. It adds concerns about the distribution of benefits between firms and consumers to the government's objective function.

For $\alpha=1$, the government pays no attention to this issue of distribution and maximises only the traditional welfare component. This captures the 'traditional', efficiency-oriented welfare maximising scenario. For $\alpha>1$, the government is industry-friendly and places a positive net weight $(\alpha-1)$ on aggregate profits, besides taking account of the traditional objective. That is, profits count more than consumers' residual income (cf. (1)). By contrast, for $\alpha<1$, the government is consumer-friendly and assigns a negative net weight $(\alpha-1)$ to profits. That is, profits count less than consumers' residual income. ${ }^{12}$

\subsection{Choice of Policy Instruments}

The distributional preferences of the government are important, as they drive the choice of policy instruments. In exploring these preferences, we apply

\section{Definition 1 Equivalent Tax-Subsidy Bundles}

Consider two tax-subsidy bundles $\left(\tau_{1}, s_{1}\right)$ and $\left(\tau_{2}, s_{2}\right)$. They are said to be equivalent

\footnotetext{
${ }^{12}$ Recall that the government objective (11) can be interpreted as a political support function. See our remarks at the end of section 2 .
} 
if and only if they induce the same energy efficiency $e_{H}$ in equilibrium; that is, if and only if $e_{H}\left(\tau_{1}, s_{1}\right)=e_{H}\left(\tau_{2}, s_{2}\right)$.

The optimality condition (8) implies that two tax-subsidy bundles $\left(\tau_{1}, s_{1}\right)$ and $\left(\tau_{2}, s_{2}\right)$ are equivalent if, and only if,

$$
\frac{1+\tau_{1}}{1-s_{1}}=\frac{1+\tau_{2}}{1-s_{2}}
$$

holds. This equivalence condition simply reflects the fact that there is an infinite number of tax-subsidy bundles that provide the same incentives for firm $H$ to invest in energy efficiency. Despite their equivalence, however, the government is not necessarily indifferent between these tax-subsidy bundles, as summarised in

\section{Proposition 1 Preferences over Policy Instruments}

Consider the equivalent tax-subsidy bundles $\left(\tau_{1}, s_{1}\right)$ and $\left(\tau_{2}, s_{2}\right)$ with $\tau_{1} \neq \tau_{2}$ and $s_{1} \neq s_{2}$. For a given standard $e_{\text {min }}$, we can state:

(i) A neutral government $(\alpha=1)$ is indifferent between two equivalent tax-subsidy bundles $\left(\tau_{1}, s_{1}\right)$ and $\left(\tau_{2}, s_{2}\right)$. That is, $W\left(\tau_{1}, s_{1}, e_{\text {min }}\right)=W\left(\tau_{2}, s_{2}, e_{\text {min }}\right)$.

(ii) A consumer-friendly government $(\alpha<1)$ prefers tax-subsidy bundle $\left(0, s_{1}\right)$ to every equivalent bundle $\left(\tau_{2}, s_{2}\right)$. That is, $W\left(0, s_{1}, e_{\text {min }}\right)>W\left(\tau_{2}, s_{2}, e_{\text {min }}\right)$, including the special case $W\left(0, s_{1}, e_{\text {min }}\right)>W\left(\tau_{2}, 0, e_{\text {min }}\right)$.

(iii) An industry-friendly government $(\alpha>1)$ prefers tax-subsidy bundle $\left(\tau_{1}, 0\right)$ to every equivalent bundle $\left(\tau_{2}, s_{2}\right)$. That is, $W\left(\tau_{1}, 0, e_{\text {min }}\right)>W\left(\tau_{2}, s_{2}, e_{\text {min }}\right)$, including the special case $W\left(\tau_{1}, 0, e_{\text {min }}\right)>W\left(0, s_{2}, e_{\text {min }}\right)$.

Proof. See appendix.

For a given standard $e_{\text {min }}$, two equivalent tax-subsidy bundles $\left(\tau_{1}, s_{1}\right)$ and $\left(\tau_{2}, s_{2}\right)$ yield the same equilibrium allocation $\left(e_{H}, e_{L}, E\right)$, and thus the same fixed costs $a_{H}$ and $a_{L}$ and the same environmental damage $D(E)$. Not surprisingly, a neutral government, which cares only about the overall outcome in terms of costs and benefits of a cleaner environment, is indifferent between equivalent policy bundles, as part (i) of proposition 1 states.

The intuition for the conclusions in parts (ii) and (iii) of this proposition is less obvious. Surprisingly, an industry-friendly government prefers an energy tax to an equivalent subsidy or tax-subsidy mix, although the financial implications of the two instruments seem to favour a subsidy from the firms' perspective. While the subsidy implies direct payments to the firms, the energy tax entails no immediate benefit to the industrial sector. Just as surprisingly, a consumer-friendly government goes for a subsidy to the firms rather than for an equivalent energy tax or tax-subsidy mix, although the financial implications for households seem to favour the energy tax. 
The subsidy payments have to be fully covered by the households' tax payments. In contrast to the subsidy, the emission tax does not cause a net tax burden on households at the aggregate level, since the revenues are handed back to them.

The key difference between the energy tax and the subsidy, however, is not the direct redistribution effect via the tax-transfer system, but the indirect one via market mechanisms. An energy tax induces firm $H$ to invest more in its product's energy efficiency, since the tax reinforces the positive impact of a rise in the physical quality gap $e_{H}-e_{L}$ on product prices, as discussed above. As a consequence of the tax, the prices of both firms increase directly and indirectly; that is, $\partial p_{i} / \partial \tau>0$ and $\left(\partial p_{i} / \partial e_{H}\right)\left(\partial e_{H} / \partial \tau\right)>0$ hold (see lemmas 1 and 2 and equilibrium prices (4)). The twofold rise in both product prices raises the revenues and profits of both firms at the expense of consumers, who end up with a lower residual income at the aggregate level. The induced redistribution through the product market makes such a tax attractive for an industry-friendly government and unattractive for a consumerfriendly government.

A subsidy, in contrast, increases energy efficiency $e_{H}$ because it reduces the costs of product quality. Since this instrument rewards investment in the energy efficiency of a product in a more targeted fashion, a subsidy increases prices only indirectly, but not directly. That is, $\left(\partial p_{i} / \partial e_{H}\right)\left(\partial e_{H} / \partial s\right)>0$ results, but $\partial p_{i} / \partial s=$

0 . Consequently, a subsidy limits redistribution from households to firms more effectively than an energy tax. For this reason, a consumer-friendly government endorses a subsidy and shies away from an emission tax, whereas an industry-friendly government does exactly the opposite.

\subsection{Optimal Emission Taxes, Subsidies, and Standards}

So far, we have discussed the preferred policy instruments of different government types. Now, we explore the optimal energy tax, subsidy and standard. To this end, we derive the marginal impact of changes in the three policy instruments:

$$
\begin{array}{r}
\frac{d W}{d \tau}=(\alpha-1) c\left[\left(e_{H}-e_{L}\right) \frac{[1-F(\widetilde{z})]^{2}+[F(\widetilde{z})]^{2}}{F^{\prime}(\widetilde{z})}+(1+\tau) \frac{d e_{H}}{d \tau} \frac{[F(\widetilde{z})]^{2}}{F^{\prime}(\widetilde{z})}\right] \\
+\left[\left(\frac{\partial D}{\partial E}+c\right) Z_{H}^{a g g}-\frac{\partial a_{H}}{\partial e_{H}}\right] \frac{d e_{H}}{d \tau}, \\
\begin{array}{r}
\frac{d W}{d s}=(\alpha-1)\left[(1+\tau) c \frac{d e_{H}}{d s} \frac{[F(\widetilde{z})]^{2}}{F^{\prime}(\widetilde{z})}+a_{H}+a_{L}\right] \\
+ \\
\left.+\left(\frac{\partial D}{\partial E}+c\right) Z_{H}^{a g g}-\frac{\partial a_{H}}{\partial e_{H}}\right] \frac{d e_{H}}{d s}
\end{array}
\end{array}
$$




$$
\begin{array}{r}
\frac{d W}{d e_{\min }}=-(\alpha-1)\left[(1+\tau) c \frac{[1-F(\widetilde{z})]^{2}+[F(\widetilde{z})]^{2}}{F^{\prime}(\widetilde{z})}+(1-s) \frac{\partial a_{L}}{\partial e_{L}}\right] \\
+\left[\left(\frac{\partial D}{\partial E}+c\right) Z_{L}^{a g g}-\frac{\partial a_{L}}{\partial e_{L}}\right],
\end{array}
$$

where we made use of the envelope theorem in (13) and (14). The first line of each derivative captures the marginal effect of the policy instrument on aggregate profits, the second line on the traditional welfare component. As before, we differentiate between a neutral, consumer-friendly and industry-friendly government.

Neutral Government $(\alpha=1) \quad$ We first consider - as a benchmark - a neutral government. Its optimal policy mix is characterised in

Proposition 2 Optimal Policy Mix of a Neutral Government $(\alpha=1)$

Consider a neutral government $(\alpha=1)$. In the subgame-perfect equilibrium, the optimal policy $\operatorname{mix}\left(\tau^{*}, s^{*}, e_{\min }^{*}\right)$ consists of a tax-subsidy bundle that fulfils the condition

$$
\tau^{*}=\left(1-s^{*}\right) \frac{[(\partial D / \partial E) / c+1] Z_{H}^{a g g}}{[1-F(\widetilde{z})]^{2} / f(\widetilde{z})}-1
$$

and a minimum energy efficiency standard that is implicitly defined by

$$
\frac{\partial a_{L}}{\partial e_{\min }^{*}}=\left(\frac{\partial D}{\partial E}+c\right) Z_{L}^{a g g} .
$$

Proof. See appendix.

For $\alpha=1$, the first lines of the derivatives (13), (14), and (15) vanish, and the second lines capture the simple trade-off that a neutral government faces. On the one hand, more energy-efficient products cut environmental damage and save energy costs, as reflected by the term $[(\partial D / \partial E)+c] Z_{i}^{a g g}$. On the other hand, more ecofriendly products increase fixed costs, as captured by the term $\partial a_{i} / \partial e_{i}$. Balancing these two opposing effects leads to the optimal tax-subsidy bundles $\left(\tau^{*}, s^{*}\right)$ and standard $e_{\min }^{*}$ which induce optimal efficiency levels $e_{H}^{*}$ and $e_{L}^{*}{ }^{13}$

Since the infinite number of tax-subsidy bundles $\left(\tau^{*}, s^{*}\right)$ that induce firm $H$ to choose the optimal energy efficiency $e_{H}$ include $\left(\tau^{*}, 0\right)$ and $\left(0, s^{*}\right)$, an energy tax alone, or a subsidy alone, is sufficient to implement the optimal solution. In addition, the energy efficiency standard $e_{m i n}^{*}$, which forces firm $L$ to raise its product quality to $e_{\text {min }}^{*}$, is necessary because the low quality firm does not respond to the

\footnotetext{
${ }^{13}$ We focus on situations in which the optimal standard $e_{m i n}^{*}$ lies in the interval $\left(0, e_{l i m}\right)$. Thus, the non-drastic standard restriction $e_{\text {min }}<e_{\text {lim }}$ prevents the government from implementing an allocation with only one firm in the market, but it does not constrain the second-best solution described by (17). We assume this kind of interior solution in the following analysis.
} 
other instruments. This justifies to some extent the use of standards, a traditional command-and-control instrument, in addition to taxes and subsidies, two marketbased instruments.

Consumer-friendly government $(\alpha<1)$ We now turn to the optimal policy mix of a consumer-friendly government, which is characterised in

Proposition 3 Optimal Policy Mix of a Consumer-Friendly Government $(\alpha<1)$ (i) Consider a consumer-friendly government $(\alpha<1)$. In the subgame-perfect equilibrium, the optimal policy mix consists of a subsidy $s^{* *}$ and a minimum energy efficiency standard $e_{m i n}^{* *}$. The optimal subsidy rate $s^{* *}$ increases with the preference parameter $\alpha$, while the optimal standard $e_{\text {min }}^{* *}$ decreases with $\alpha$. That is, $d s^{* *} / d \alpha>0$ and $d e_{\text {min }}^{* *} / d \alpha<0$.

(ii) Measured in terms of induced energy efficiency levels $e_{H}$ and $e_{L}$, the optimal subsidy $s^{* *}$ is less eco-friendly, and the optimal standard $e_{\min }^{* *}$ is more restrictive, than the corresponding tax-subsidy bundle $\left(\tau^{*}, s^{*}\right)$ and standard $e_{\min }^{*}$ of a neutral government. That is,

$$
e_{H}\left(s^{* *}\right)<e_{H}\left(\tau^{*}, s^{*}\right) \quad \text { and } \quad e_{\min }^{* *}>e_{\min }^{*}
$$

Proof. See appendix.

As Proposition 3 shows, consumer friendliness does not only drive the choice of policy instruments, but also the extent of their use. A consumer-friendly government implements a subsidy instead of an energy tax, as a subsidy implies less redistribution from households to firms than an energy tax, for reasons already discussed above. But although a subsidy limits redistribution at the expense of households, it does not eliminate this kind of redistribution altogether. Consumers still have to finance the subsidy payment and additionally suffer from higher product prices in response to a greater energy efficiency $e_{H}$.

The implications of a standard are very different. A higher standard narrows the quality gap, and thus the energy cost differential, between product types. The high quality and low quality products become more similar, leading to intensified price competition. As a consequence, product prices, revenues and profits of both firms decline to the benefit of the consumers whose aggregate residual income rises. These redistributional implications favour a standard over a subsidy. And the more consumer-friendly the government is (i.e. the lower $\alpha$ ), the more attention it pays to redistributional effects, leading to a stricter standard and a lower subsidy, as part (i) of proposition 3 states. 
This focus on a standard, rather than a subsidy, is also reflected in the resulting allocation. Compared to a neutral government, a consumer-friendly government enforces a greater energy efficiency of the low quality product, but accepts a lower energy efficiency of the high quality product, as part (ii) of proposition 3 argues. Again, this outcome stems from the distributional goal.

Industry-friendly government $(\alpha>1)$ Let us finally consider an industryfriendly government. Its optimal policy mix is characterised in

Proposition 4 Optimal Policy Mix of an Industry-Friendly Government $(\alpha>1)$

(i) Consider an industry-friendly government $(\alpha>1)$. Its optimal policy mix consists of an energy tax $\tau^{* * *}$ and a minimum energy efficiency standard $e_{\text {min }}^{* * *}$. The optimal tax rate $\tau^{* * *}$ increases with the preference parameter $\alpha$, while the optimal standard $e_{\text {min }}^{* * *}$ decreases with $\alpha$. That is, $d \tau^{* * *} / d \alpha>0$ and $d e_{\text {min }}^{* * *} / d \alpha<0$.

(ii) Measured in terms of induced energy efficiency levels $e_{H}$ and $e_{L}$, the optimal tax $\tau^{* * *}$ is more eco-friendly, and the optimal standard $e_{\min }^{* * *}$ is laxer, than the corresponding tax-subsidy bundle $\left(\tau^{*}, s^{*}\right)$ and standard $e_{\text {min }}^{*}$ of a neutral government. That is,

$$
e_{H}\left(\tau^{* * *}\right)>e_{H}\left(\tau^{*}, s^{*}\right) \quad \text { and } \quad e_{\min }^{* * *}<e_{\min }^{*} .
$$

Proof. See appendix.

By now, the economic intuition for these results is clear. We have already explored that an industry-friendly government implements an energy tax and shies away from a subsidy for redistribution reasons. As discussed above, an emission tax implicitly redistributes from households to firms. A standard, by contrast, enriches consumers at the expense of firms. Nevertheless, a standard cannot be completely avoided, but, not surprisingly, an industry-friendly government distorts its policy towards the energy tax and away from the standard. This distortion is the more pronounced, the more industry-friendly the government (i.e. the greater the preference parameter $\alpha$ ).

The distorted policy mix is reflected in the resulting allocation. Compared to a neutral government, an industry-friendly government induces a higher energy efficiency of the high quality product, but allows a lower energy efficiency of the low quality product.

\section{Discussion}

We have so far analysed three widespread policy instruments. In this section, we discuss informally two alternative instruments, a discriminatory investment subsidy 
and a rebate for the purchase of an energy efficient product. We argue that exploring these alternative instruments does not lead to significant additional insights, thus justifying our initial selection of instruments. Furthermore, we sketch two possible extensions of our model, to consider energy costs in production and endogenous consumption intensities. We argue that our results prove to be robust under reasonable and empirically supported assumptions.

\subsection{Alternative Policy Instruments}

Let us start by analysing two alternative policy instruments. First, the government could subsidise only the investment of the firm with the more energy efficient product. Such a discriminatory subsidy could replace the non-discriminatory subsidy applied above. After all, the non-discriminatory investment subsidy does not affect the quality decision of the firm whose product just fulfils the minimum standard. It just generates a windfall profit to the low quality firm. Replacing the non-discriminatory subsidy by a discriminatory one would further limit redistribution in favour of firms, without affecting energy efficiency and pollution.

Such a change of policy, however, would only reinforce our key conclusions. A consumer-friendly government, which already prefers a non-discriminatory subsidy to an energy tax, would endorse even more a discriminatory subsidy. And an industry-friendly government, which prefers an energy tax to a non-discriminatory subsidy, would object even more to a discriminatory subsidy.

Second, the government could grant a rebate to consumers who buy the high quality product. For instance, this rebate could take the form of $\delta_{H} p_{H}, \delta_{H} \geq 0$, so that households would effectively pay $\left(1-\delta_{H}\right) p_{H}$ for the high quality product while firm $H$ would still receive $p_{H}$. Interestingly, a consumer-friendly government would not prefer this instrument to the discriminatory investment subsidy discussed above. To see this, note that a rebate $\delta_{H} p_{H}$ to consumers would not affect the firms' market shares, which would still be described by equation (5). Like an investment subsidy, a rebate would provide an incentive for firm $H$ to invest in a more energy efficient product, which would indirectly raise price $p_{H}$. But, unlike an investment subsidy, this rebate would also directly increase the price of the eco-friendly product, which would then be

$$
p_{H}=\frac{1+\tau}{1-\delta_{H}} c\left(e_{H}-e_{L}\right) \frac{1-F(\widetilde{z})}{F^{\prime}(\widetilde{z})} .
$$

As $(20)$ and (4) show, the direct effect of the rebate $\delta_{H}$ on price $p_{H}$, i.e. $\partial p_{H} / \partial \delta_{H}$, resembles the direct effect of the energy $\operatorname{tax} \tau$, i.e. $\partial p_{H} / \partial \tau$. And because of this direct impact on prices, a consumer-friendly government prefers a (discriminatory) investment subsidy not only to an energy tax but also to a rebate to eco-friendly 
consumers.

Also, an industry-friendly government prefers an energy tax to a consumer rebate. The reason is that the above rebate directly raises only the price of the high quality product. ${ }^{14}$ In contrast, an energy tax directly increases the prices of both the high quality and low quality products, as outlined in sections 3 and 4. All in all, industry-friendly and consumer-friendly governments both regard a consumer rebate as inferior, either to an energy tax or to a (discriminatory) investment subsidy.

\subsection{Extensions of Model}

To check the robustness of our results, we finally discuss two extensions of our model. First, we take into account that energy costs also contribute to production costs. More precisely, let us assume that both firms need $\mu$ energy units to produce one unit of output, where $\mu$ is given exogenously. (All other assumptions are unaltered.) Then, marginal production costs are $(1+\tau) c \mu$, and both equilibrium prices $p_{H}$ and $p_{L}$ rise by the very same amount $(1+\tau) c \mu$. That is, these energy production costs are fully passed on to and born by households. This level effect on prices does not change each firm's market share nor does it affect the incentives to invest in more energy efficient products. The optimal instrument choices and the optimal environmental policies remain the same, too - given that all energy tax revenues are handed back to households, as assumed before.

The second extension that we sketch is less straightforward. We continue to assume that the market is fully covered. But we now determine the consumption intensity endogenously. For instance, each household still purchases one car, but the number of miles driven in the car depends on fuel prices. To see whether our model is robust with respect to this extension, we briefly discuss whether an endogenous consumption intensity alters the characteristics of the market equilibrium.

Recall that the market equilibrium exhibits two decisive features: First, both prices $p_{H}$ and $p_{L}$ increase with energy tax $\tau$. And second, the energy efficiency of the high quality product $e_{H}$ also increases with tax $\tau$. These characteristics might not hold if the consumption intensity is endogenous. The reason is that a higher energy price depresses the households' consumption intensities. If this effect is strong enough and consumption intensities drop sufficiently, then more households start to prefer the low quality product, and price competition is reinforced. Since demand for the more eco-friendly good falls, the incentive to invest in its energy efficiency declines, too. Hence, an energy tax can lead to lower prices $p_{H}$ and $p_{L}$ and to a lower energy efficiency $e_{H}$. Such a perverse market outcome would undermine our

\footnotetext{
${ }^{14}$ The price $p_{L}$ of the low quality product is still given by the corresponding expression in (4).
} 
key conclusions.

We argue, however, that such an outcome does not occur under reasonable assumptions. To make our point as simple as possible, let us assume that household $h$ 's utility is given by $V_{h}=\eta_{h} U\left(z_{h}\right)-m_{h}$, where residual income $m_{h}=$ $x-p_{i}-t\left(\bar{e}-e_{i}\right) z_{h}+b$ is defined as above and $U^{\prime}(z)>0$ and $U^{\prime \prime}(z)<0$ hold. The new preference parameter $\eta_{h}$ is distributed according to a distribution function $F(\eta)$ which has the same properties as $F(z)$ above. Intensity $z_{h}$ is now determined endogenously. For convenience, the intertemporal elasticity of substitution $\sigma=-U^{\prime}(z) /\left[U^{\prime \prime}(z) z\right]$ is assumed to be constant. Then, the prices $p_{H}$ and $p_{L}$ and the energy efficiency $e_{H}$ increase with energy $\operatorname{tax} \tau$ if and only if the elasticity $\sigma$ is smaller than one, i.e. $\partial p_{i} / \partial \tau>0$ and $\partial e_{H} / \partial \tau>0 \Leftrightarrow \sigma<1$. Translated into demand elasticities, this means that the key features of the market equilibrium remain valid if - for a given product choice and energy efficiency - the energy price elasticity of the consumption intensity, and thus of energy demand, ranges between 0 and $-1 .^{15}$ As this elasticity condition indicates, a fully inelastic demand in terms of consumption intensity is not necessary for our results to hold, demand only has to be sufficiently inelastic.

To see whether this condition is fulfilled in reality, note that our elasticity condition refers to the change in consumption intensity for given product choice and quality. That is, it refers to the short-term demand elasticity of consumption intensity, and thus of energy demand (cf. Reiss and White, 2005). And there is indeed strong empirical evidence that this short-term elasticity is close to zero. Take the demand for automobile fuel, for instance. Goodwin et al.'s (2004) review of the empirical literature finds that 46 price elasticities of fuel consumption - calculated by dynamic estimation methods using time-series data - range from -0.01 to -0.57 , with a mean of $-0.25 .{ }^{16}$ These estimates are broadly in line with the figures of other reviews (for instance, OECD, 2006).

Moreover, recent studies find that the short-term price elasticity of fuel demand has declined over time (Hughes et al., 2008, Small and Van Dender, 2007). Analysing US data, Hughes et al. (2008) estimate that the short-term price elasticity of fuel demand for the period 1975 to 1980 ranges from -0.32 to -0.34 , whereas the elasticity for the period from 2001 to 2006 ranges from -0.034 to -0.077 .

In the long-term, demand is more elastic due to more fuel efficient vehicles, as captured in our model. In the studies reviewed by Goodwin et al. (2004), the mean long-term elasticity is -0.64. Indeed, Austin and Dinan (2005) and Small and

\footnotetext{
${ }^{15}$ Technical details can be obtained upon request.

${ }^{16}$ The mean elasticity calculated by static estimation methods is -0.43 and thus also consistent with our condition.
} 
Van Dender (2007) attribute about 50\% and more of the long-term elasticity of fuel demand to more fuel efficient cars. These empirical studies support our focus on the importance of energy efficiency for energy conservation.

Establishing relationships between energy prices and the consumption intensity of specific household appliances, such as washing machines and TV sets, is certainly a difficult task. While there appears to be a lack of product-specific studies, a number of papers analyse the price elasticity of residential electricity in general. Espey and Espey (2004) analyse 36 papers published between 1971 and 2000. In their data-set, the short-term price elasticity of residential electricity ranges from -0.004 to -2.01 , with a mean of -0.35 and a median of -0.28 . While there is some variation in the results, most studies find that residential electricity demand, like fuel demand, is fairly price-inelastic (see also OECD, 2006/2008).

In a more recent study, Reiss and White (2005) stress the heterogeneity in households' price elasticities. Analysing data from California, they estimate that the mean short-term elasticity of residential electricity is -0.35 . Even more interestingly, the corresponding elasticity of households who have neither electric space heating nor air-conditioning is very close to zero, with -0.08 . That is, households who just use energy for washing machines, refrigerators, television sets and the like practically fit our description of households whose consumption intensity is fully price-inelastic. Again, these findings suggest that our elasticity condition is in line with empirical evidence.

There is evidence that environmental policy indeed causes changes in the design of household appliances. Newell et al. (1999) find, for instance, that more than half of the energy efficiency gains of room air-conditioners and all of the energy efficiency gains of water heaters are induced by changes in energy prices and efficiency standards.

\section{Conclusion}

In this paper, we analyse environmental policy in the case of vertically differentiated markets and endogenous energy efficiency levels. In particular, we explore how distributional goals in addition to environmental goals affect the choice of environmental policy instruments and the extent to which these instruments are applied. Our paper shows that a minimum energy efficiency standard is always part of the optimal policy mix, regardless of the government's distributional preferences. A consumer-friendly government imposes a particularly strict standard and grants a subsidy to firms for investments in more energy efficient products. In contrast, an industry-friendly government introduces only a lax product standard and addition- 
ally levies a tax on energy.

We briefly argue that our conclusions are robust against two important extensions. The first extension considers energy costs in production while the second allows for endogenous consumption intensities. In the latter case, our fundamental market characteristics remain unchanged if the short-term energy demand remains sufficiently price-inelastic. We provide some empirical evidence that our elasticity condition is indeed reasonable.

\section{Appendix}

Proof of Lemma 1 (i) No 'boundary' equilibrium: We start by excluding any price competition equilibria with $p_{i}=0$. (Negative prices can obviously never emerge in equilibrium.) Note first that the high quality firm $H$ can always set a positive price and generate positive revenues, no matter what non-negative price firm $L$ chooses. By contrast, the low quality firm $L$ is not able to charge a positive price and to gain a positive market share if $p_{H} \leq(1+\tau) c\left(e_{H}-e_{L}\right) \underline{z}=: \underline{p_{H}}$ holds, which follows directly from (2). For $p_{L} \geq 0$, however, $\partial \pi_{H} /\left.\partial p_{H}\right|_{p_{H}=p_{H}} \geq 1-\underline{z} F^{\prime}(\underline{z})>0$ results (see, particularly, property (iii) of the distribution function). Thus, $p_{H} \leq p_{H}$ cannot be an equilibrium. If an equilibrium exists, then $p_{H}>p_{H}$ holds, implying that $p_{L}>0$ (since, for $p_{H}>p_{H}$, there always exists a positive $p_{L}<p_{H}$ that generates positive revenues and thus dominates $p_{L}=0$; see, again, (2)). This equilibrium is then described by (2) and (4).

Existence of unique 'interior' equilibrium: If condition (5), which follows from (2) and (4), defines a unique threshold $\widetilde{z} \in(\underline{z}, \bar{z})$, and thus unique prices $p_{H}$ and $p_{L}$ (see, again, (4)), then there exists a unique equilibrium. We, therefore, show that a unique threshold $\widetilde{z} \in(\underline{z}, \bar{z})$ exists. We first differentiate $[1-2 F(z)] / F^{\prime}(z)=: \Omega(z)$ with respect to $z$, implying that

$$
\frac{\partial \Omega(z)}{\partial z}<0 \Leftrightarrow F^{\prime \prime}(z)>-2 \frac{\left[F^{\prime}(z)\right]^{2}}{1-2 F(z)} .
$$

results for $F(z) \in[0,0.5] \Leftrightarrow z \in\left[\underline{z}, z^{\text {crit }}\right]$, where $z^{\text {crit }}$ is defined as $z^{\text {crit }}: F\left(z^{\text {crit }}\right)=$ 0.5. Moreover, inequality $F^{\prime \prime}(z)>-2 \frac{\left[F^{\prime}(z)\right]^{2}}{1-F(z)}$ holds under property (iv) of the distribution function, and $-2 \frac{\left[F^{\prime}(z)\right]^{2}}{1-F(z)} \geq-2 \frac{\left[F^{\prime}(z)\right]^{2}}{1-2 F(z)}$ results for $z \in\left[\underline{z}, z^{\text {crit }}\right]$. Thus, the term $\Omega(z)$ continuously decreases with $z$ in the interval $\left[\underline{z}, z^{\text {crit }}\right]$. Additionally, $\Omega(\underline{z})=1 / F^{\prime}(\underline{z})>\underline{z}$ (which follows from property (iii) of the distribution function), $\Omega\left(z^{\text {crit }}\right)=0$, and, for $z \in\left(z^{\text {crit }}, \bar{z}\right], \Omega(z)<0$ hold. Also, in the interval $[\underline{z}, \bar{z}]$, the term $z$ is obviously positive and continuously increasing from $\underline{z}$ to $\bar{z}$. Given all these values and the fact that $\Omega(z)$ is strictly decreasing, and $z$ is strictly increasing, 
with $z$, the intermediate value theorem implies that the equilibrium threshold $\widetilde{z}$ is uniquely determined by $\widetilde{z}-\Omega(\widetilde{z})=0$ or condition (5), with $\widetilde{z} \in\left[\underline{z}, z^{\text {crit }}\right]$. Moreover, $\widetilde{z} \in\left[\underline{z}, z^{\text {crit }}\right]$ implies that $F(z)<0.5$. Thus $p_{H}>p_{L}$ follows from (4)).

(ii) The equilibrium threshold $\widetilde{z}$ only depends on the properties of the distribution function, as (5) directly shows, and is thus independent of tax $\tau$ and energy effectiveness levels $e_{H}$ and $e_{L}$; and so is then $y_{H}=1-F(\widetilde{z})$ and $y_{L}=F(\widetilde{z})$.

(iii) Since $\widetilde{z}$ is independent of $\tau, e_{H}$, and $e_{L}$, simple differentiation of (4) yields $\frac{\partial p_{H}}{\partial e_{H}}=(1+\tau) c \frac{[1-F(\widetilde{z})]}{F^{\prime}(\widetilde{z})}>0, \frac{\partial p_{H}}{\partial e_{L}}=-(1+\tau) c \frac{[1-F(\widetilde{z})]}{F^{\prime}(\widetilde{z})}<0, \frac{\partial p_{L}}{\partial e_{H}}=(1+\tau) c \frac{F(\widetilde{z})}{F^{\prime}(\widetilde{z})}>$ $0, \frac{\partial p_{L}}{\partial e_{L}}=-(1+\tau) c \frac{F(\widetilde{z})}{F^{\prime}(\widetilde{z})}<0, \frac{\partial p_{H}}{\partial \tau}=c\left(e_{H}-e_{L}\right) \frac{[1-F(\widetilde{z})]}{F^{\prime}(\widetilde{z})}>0$, and finally $\frac{\partial p_{L}}{\partial d \tau}=$ $c\left(e_{H}-e_{L}\right) \frac{F(\widetilde{z})}{F^{\prime}(\widetilde{z})}>0$.

Proof of Lemma 2 (i) To avoid misunderstandings, let us relabel the two firms as firm 1 and firm 2. Inserting equilibrium values (4) and (5) into (3) yields firm 1's piecewise defined profit function

$$
\pi_{1}\left(e_{1} ; e_{2}\right)=\left\{\begin{array}{ll}
(1+\tau) c\left(e_{2}-e_{1}\right) \frac{[F(\widetilde{z})]^{2}}{F^{\prime}(\tilde{z})}-(1-s) a\left(e_{1}\right) & \text { for } \quad e_{1}<e_{2} \\
(1+\tau) c\left(e_{1}-e_{2}\right) \frac{[1-F(\bar{z})]^{2}}{F^{\prime}(\widetilde{z})}-(1-s) a\left(e_{1}\right) & \text { for } \quad e_{1} \geq e_{2}
\end{array} .\right.
$$

For all $e_{2}$, firm 1's profit function (22) is continuous in $e_{1}$, with local maxima at $e_{1}=e_{\min }$ and $e_{1}=e_{H}$ (where $e_{H}$ is defined by (8)), as implied by (6) and (7). ${ }^{17}$ Comparing the two maxima yields firm 1's piecewise defined reaction function

$$
e_{1}=\left\{\begin{array}{ll}
e_{H} & \text { for } \quad e_{2}<\widetilde{e} \\
e_{\min } & \text { for } \quad e_{2} \geq \widetilde{e}
\end{array},\right.
$$

where $\widetilde{e}$ is defined by $\widetilde{e}: \pi_{1}\left(e_{H} ; \widetilde{e}\right)=\pi_{1}\left(e_{\min } ; \widetilde{e}\right)$, with $\widetilde{e} \in\left(e_{\min }, e_{H}\right)$. Note that both $e_{H}$ and $e_{m i n}$ are independent of $e_{2}$, as (6) and (7) show. Then the property $\widetilde{e} \in\left(e_{\min }, e_{H}\right)$ follows from the inequalities $\pi_{1}\left(e_{H} ; e_{m i n}\right)>\pi_{1}\left(e_{\text {min }} ; e_{\text {min }}\right)$ and $\pi_{1}\left(e_{H} ; e_{2} \geq e_{H}\right)<\pi_{1}\left(e_{m i n} ; e_{2} \geq e_{H}\right)$ (which in turn follows from (6) and (7)) and the derivatives $\partial \pi_{1}\left(e_{H} ; e_{2}\right) / \partial e_{2}<0$ for $e_{2} \in\left[e_{m i n}, e_{H}\right]$ and $\partial \pi_{1}\left(e_{m i n} ; e_{2}\right) / \partial e_{2}>0$.

Analogously, we derive firm 2's piecewise defined reaction curve - just substitute index 1 for 2 and vice versa. Therefore, only two equilibria are possible: Either firm 1 chooses $e_{H}$ and firm 2 chooses $e_{\min }$ or vice versa. ${ }^{18}$

(ii) Using $\frac{\partial \pi_{H}}{\partial e_{H}}=0$ (see (6) or (8)), comparative statics yields

$$
\frac{d e_{H}}{d \tau}=\frac{\partial a_{H} / \partial e_{H}}{(1+\tau) \partial^{2} a_{H} / \partial e_{H}^{2}}>0 \quad \text { and } \quad \frac{d e_{H}}{d s}=\frac{\partial a_{H} / \partial e_{H}}{(1-s) \partial^{2} a_{H} / \partial e_{H}^{2}}>0 .
$$

\footnotetext{
${ }^{17}$ One of the two local maxima disappears if $e_{2}=e_{\min }$ or $e_{2} \geq e_{H}$.

${ }^{18}$ These equilibria additionally require that $e_{\min } \leq e_{\text {lim }}$ is sufficiently small, so that both firms can set sufficiently high prices and realise non-negative profits. Otherwise, one firm would prefer to exit the market.
} 
Obviously, $\frac{d e_{H}}{d e_{\text {min }}}=0$ results.

(iii) Equation (9) directly implies $\frac{d e_{L}}{d e_{\min }}=1$ and $\frac{d e_{L}}{d \tau}=\frac{d e_{L}}{d s}=0$.

Proofs of the Proposition 1 (i) Consider two equivalent tax-subsidy bundles $\left(\tau_{1}, s_{1}\right)$ and $\left(\tau_{2}, s_{2}\right)$, i.e. (12) holds. Since threshold $\widetilde{z}$ is independent of $\operatorname{tax} \tau$ and subsidy $s$ (see lemma 1, part (ii)), and since $e_{H}\left(\tau_{1}, s_{1}\right)=e_{H}\left(\tau_{2}, s_{2}\right)$ holds, $a_{H}\left(\tau_{1}, s_{1}\right)=a_{H}\left(\tau_{2}, s_{2}\right)$ and, for given $e_{\text {min }}$ (and thus $e_{L}$ and $\left.a_{L}\right), E\left(\tau_{1}, s_{1}, e_{\text {min }}\right)=$ $E\left(\tau_{2}, s_{2}, e_{\text {min }}\right)$ result (see (8), (9), and (10)). Thus the traditional welfare component $x-c E-D(E)-a_{H}-a_{L}=: \Phi$ is equal for the two policy bundles $\left(\tau_{1}, s_{1}\right)$ and $\left(\tau_{2}, s_{2}\right)$ and for given $e_{\text {min }}$, i.e. $\Phi\left(\tau_{1}, s_{1}, e_{\text {min }}\right)=\Phi\left(\tau_{2}, s_{2}, e_{\text {min }}\right)$. Then $\left.W\left(\tau_{1}, s_{1}, e_{\text {min }}\right)\right|_{\alpha=1}=$ $\Phi\left(\tau_{1}, s_{1}, e_{\text {min }}\right)=\Phi\left(\tau_{2}, s_{2}, e_{\text {min }}\right)=\left.W\left(\tau_{2}, s_{2}, e_{\text {min }}\right)\right|_{\alpha=1}$, as argued in part (i) of the proposition.

(ii) and (iii) Welfare comparison: Consider again two equivalent tax-subsidy bundles $\left(\tau_{1}, s_{1}\right)$ and $\left(\tau_{2}, s_{2}\right)$. Then

$$
\begin{gathered}
W\left(\tau_{1}, s_{1}, e_{\text {min }}\right) \gtreqless W\left(\tau_{2}, s_{2}, e_{\text {min }}\right) \\
\Leftrightarrow(\alpha-1)\left[\pi_{H}\left(\tau_{1}, s_{1}, e_{m i n}\right)+\pi_{L}\left(\tau_{1}, s_{1}, e_{m i n}\right)\right] \\
\gtreqless(\alpha-1)\left[\pi_{H}\left(\tau_{2}, s_{2}, e_{m i n}\right)+\pi_{L}\left(\tau_{2}, s_{2}, e_{m i n}\right)\right] \\
\Leftrightarrow(\alpha-1)\left[\left(1+\tau_{1}\right) c\left(e_{H}-e_{L}\right) \frac{(1-F)^{2}+F^{2}}{F^{\prime}}-\left(1-s_{1}\right) a_{H}-\left(1-s_{1}\right) a_{L}\right] \\
\gtreqless(\alpha-1)\left[\left(1+\tau_{2}\right) c\left(e_{H}-e_{L}\right) \frac{(1-F)^{2}+F^{2}}{F^{\prime}}-\left(1-s_{2}\right) a_{H}-\left(1-s_{2}\right) a_{L}\right] \\
\Leftrightarrow(\alpha-1)\left(1-s_{1}\right)\left[\frac{\left(1+\tau_{1}\right)}{\left(1-s_{1}\right)} c\left(e_{H}-e_{L}\right) \frac{(1-F)^{2}+F^{2}}{F^{\prime}}-a_{H}-a_{L}\right] \\
\gtreqless(\alpha-1)\left(1-s_{2}\right)\left[\frac{\left(1+\tau_{2}\right)}{\left(1-s_{2}\right)} c\left(e_{H}-e_{L}\right) \frac{(1-F)^{2}+F^{2}}{F^{\prime}}-a_{H}-a_{L}\right] \\
\Leftrightarrow(1-\alpha)\left(s_{1}-s_{2}\right)\left[\frac{\left(1+\tau_{1}\right)}{\left(1-s_{1}\right)} c\left(e_{H}-e_{L}\right) \frac{(1-F)^{2}+F^{2}}{F^{\prime}}-a_{H}-a_{L}\right] \gtreqless 0
\end{gathered}
$$

where, for given $e_{\min }$ (and thus $e_{L}$ and $a_{L}$ ), inequality (26) follows from the relation $\Phi\left(\tau_{1}, s_{1}, e_{m i n}\right)=\Phi\left(\tau_{2}, s_{2}, e_{m i n}\right)$; inequalities (27) and (28) follow from (3), (4) and (5); inequality (29) follows from $e_{H}\left(\tau_{1}, s_{1}\right)=e_{H}\left(\tau_{2}, s_{2}\right), a_{H}\left(\tau_{1}, s_{1}\right)=a_{H}\left(\tau_{2}, s_{2}\right)$ and the equivalence condition (12). (Here, we wrote, for short, $F$ and $F^{\prime}$ instead of $F(\widetilde{z})$ and $F^{\prime}(\widetilde{z})$.) 
As discussed above, we focus on policies that allow both firms to realise nonnegative profits, i.e. $\pi_{H}+\pi_{L} \geq 0$ (and thus to stay in the market). Then the term in the square bracket of inequality (29) is positive.

Consumer-friendly government: Consider a consumer-friendly government, i.e. $\alpha<1$. In this case, inequality (29) implies that $W\left(0, s_{1}, e_{\min }\right)>W\left(\tau_{2}, s_{2}, e_{\min }\right) \Leftrightarrow$ $s_{1}-s_{2}>0$. Indeed, for $\tau_{1}=0$, equivalence condition (12) leads to $s_{1}-s_{2}=$ $\frac{\tau_{2}}{1+\tau_{2}}\left(1-s_{2}\right)>0$ for all $s_{2} \in[0,1)$. This proves part (ii) of proposition 1 .

Industry-friendly government: Next, consider an industry-friendly government, i.e. $\alpha>1$. In this case, inequality (29) directly implies that $W\left(\tau_{1}, 0, e_{\min }\right)>$ $W\left(\tau_{2}, s_{2}, e_{\text {min }}\right) \Leftrightarrow s_{1}-s_{2}<0$. Indeed, since $s_{1}=0$ and $s_{2} \neq s_{1}$ (otherwise, the two bundles $\left(\tau_{1}, 0\right)$ and $\left(\tau_{2}, s_{2}\right)$ were identical), $s_{2}>0$ and $\tau_{1}>\tau_{2}$ hold (otherwise, the two bundles $\left(\tau_{1}, 0\right)$ and $\left(\tau_{2}, s_{2}\right)$ were not equivalent), and thus $s_{1}-s_{2}=-s_{2}<0$ results. This proves $W\left(\tau_{1}, 0, e_{\text {min }}\right)>W\left(\tau_{2}, s_{2}, e_{\text {min }}\right)$, as stated in part (iii) of proposition 1.

Proof of Proposition 2 For $\alpha=1$, the first order conditions $\frac{d W}{d \tau}=0 \Leftrightarrow \frac{d W}{d s}=0$ and $\frac{d W}{d e_{\min }}=0$ lead to $\frac{\partial a_{H}}{\partial e_{H}}=\left(\frac{\partial D}{\partial E}+c\right) Z_{H}^{a g g}$ and $\frac{\partial a_{L}}{\partial e_{L}}=\left(\frac{\partial D}{\partial E}+c\right) Z_{L}^{a g g}$ (see (13), (14), and (15)). Inserting (8) and (9) into these terms yields the optimal policy mix (16) and (17). Obviously, one of the two first order conditions $\frac{d W}{d \tau}=0$ and $\frac{d W}{d s}=0$ is redundant, and the solution contains a variety of equivalent tax-subsidy bundles that imply that the induced efficiency level $e_{H}$ fulfils these first order conditions. (Cf. proposition 1, part (i), and equivalence condition (12).)

The second order conditions are fulfilled, since $\left.\frac{d^{2} W}{d \tau^{2}}\right|_{\tau=\tau^{*}}=-\left[\frac{\partial^{2} D}{\partial E^{2}}\left(Z_{H}^{a g g}\right)^{2}+\frac{\partial^{2} a_{H}}{\partial e_{H}^{2}}\right]\left(\frac{d e_{H}}{d \tau}\right)^{2}<0$ (or, alternatively, $\left.\left.\frac{d^{2} W}{d s^{2}}\right|_{s=s^{*}}=-\left[\frac{\partial^{2} D}{\partial E^{2}}\left(Z_{H}^{a g g}\right)^{2}+\frac{\partial^{2} a_{H}}{\partial e_{H}^{2}}\right]\left(\frac{d e_{H}}{d s}\right)^{2}<0\right)$, $\frac{d^{2} W}{d e_{\min }^{2}}=-\left[\frac{\partial^{2} D}{\partial E^{2}}\left(Z_{L}^{a g g}\right)^{2}+\frac{\partial^{2} a_{L}}{\partial e_{L}^{2}}\right]<0$, and $\frac{d^{2} W}{d \tau^{2}} \frac{d^{2} W}{d e_{\min }^{2}}-\left(\frac{d^{2} W}{d \tau d e_{m i n}}\right)^{2}=\left[\frac{\partial^{2} D}{\partial E^{2}}\left(Z_{H}^{a g g}\right)^{2} \frac{\partial^{2} a_{L}}{\partial e_{L}^{2}}+\frac{\partial^{2} a_{H}}{\partial e_{H}^{2}}\left[\frac{\partial^{2} D}{\partial E^{2}}\left(Z_{L}^{a g g}\right)^{2}+\frac{\partial^{2} a_{L}}{\partial e_{L}^{2}}\right]\right]\left(\frac{d e_{H}}{d \tau}\right)^{2}>0$ (or, alternatively, $\frac{d^{2} W}{d s^{2}} \frac{d^{2} W}{d e_{m i n}^{2}}-\left(\frac{d^{2} W}{d s d e_{m i n}}\right)^{2}>0$ ).

Proof of Proposition 3 (i) Proposition 1, part (ii), implies that any tax-subsidy bundle $\left(\tau_{2}, s_{2}\right)$ with $\tau_{2}>0$ cannot be optimal, as a consumer-friendly government prefers the equivalent tax-subsidy bundle $\left(0, s_{1}\right)$; that is, $W\left(0, s_{1}, e_{\min }\right)>$ $W\left(\tau_{2}, s_{2}, e_{\min }\right)$. Thus, the optimal policy mix is described by the first order conditions $d W / d s=0$ and $d W / d e_{\min }=0$ (see (14) and (15)). ${ }^{19}$

\footnotetext{
${ }^{19}$ The second order conditions are fulfilled for $\alpha=1$, as argued above (see proof of proposition 2 ). Using continuity arguments, we can show that the second order conditions are also fulfilled for $\alpha$ sufficiently close to one.
} 
Then, using $d W / d s=0$ and $d W / d e_{\min }=0$, comparative statics leads to

$$
\operatorname{sg} \frac{d s}{d \alpha}=\operatorname{sg}\left[\frac{d^{2} W}{d e_{\min } d \alpha} \frac{d^{2} W}{d s d e_{\min }}-\frac{d^{2} W}{d s d \alpha} \frac{d^{2} W}{d e_{\min }^{2}}\right]
$$

where $\frac{d^{2} W}{d s d e_{\min }}=(\alpha-1) \frac{\partial a_{L}}{\partial e_{L}}-\frac{\partial^{2} D}{\partial E^{2}} Z_{L}^{a g g} Z_{H}^{a g g} \frac{d e_{H}}{d s}<0$ for $\alpha<1, \frac{d^{2} W}{d s d \alpha}=c \frac{d e_{H}}{d s} \frac{[F(\widetilde{z})]^{2}}{F^{\prime}(\widetilde{z})}+a_{H}+$ $a_{L}>0$, and $\frac{d^{2} W}{d e_{\min } d \alpha}=-\left[c \frac{[1-F(\bar{z})]^{2}+[F(\bar{z})]^{2}}{F^{\prime}(\tilde{z})}+(1-s) \frac{\partial a_{L}}{\partial e_{L}}\right]<0$. These inequalities, together with $\frac{d^{2} W}{d e_{\min }^{2}}<0$ (see footnote 17 on second order conditions), imply that $d s^{* *} / d \alpha>0$, as stated in part (i) of proposition 3 .

Similarly, comparative statics yields

$$
\operatorname{sg} \frac{d e_{\min }^{* *}}{d \alpha}=\operatorname{sg}\left[\frac{d^{2} W}{d s d e_{\min }} \frac{d^{2} W}{d s d \alpha}-\frac{d^{2} W}{d s^{2}} \frac{d^{2} W}{d e_{\min } d \alpha}\right]
$$

where $\frac{d^{2} W}{d s d e_{\min }}<0$ for $\alpha<1, \frac{d^{2} W}{d s d \alpha}>0$, and $\frac{d^{2} W}{d e_{\min } d \alpha}<0$ (see above), together with $\frac{d^{2} W}{d s^{2}}<0$ (see, again, footnote 17 on second order conditions), imply that $d e_{m i n}^{* *} / d \alpha<0$, as stated in part (i) of proposition 3 .

(ii) Recall that any welfare-maximising tax-subsidy bundle $\left(\tau^{*}, s^{*}\right)$ can be replaced by an equivalent bundle $\left(0, s_{1}^{*}\right)$ that also maximises welfare $W$ for $\alpha=1$ (see propositions 1 and 2). In addition, $d s / d \alpha$ is a continuous function of $\alpha$ because, as can be shown, all terms of this derivative are continuous in $\alpha$ (continuity theorem). The optimal subsidy $s^{* *}$ is thus a continuous function of $\alpha$, with $d s^{* *} / d \alpha>0$ (see above) and $\lim _{\alpha \rightarrow 1} s^{* *}=s_{1}^{*}$. Consequently, $\left.s^{* *}\right|_{\alpha<1}<s_{1}^{*}$ holds. Then, $e_{H}\left(0, s^{* *}\right)<e_{H}\left(0, s_{1}^{*}\right)=e_{H}\left(\tau^{*}, s^{*}\right)$, where the inequality sign follows from $d e_{H} / d s>0$ and the equals sign from definition 1 .

Similarly, $d e_{\min } / d \alpha$ is a continuous function of $\alpha$, since all terms of this derivative are continuous in $\alpha$. The optimal standard $e_{\min }^{* *}$ is thus a continuous function of $\alpha$, with $d e_{m i n}^{* *} / d \alpha<0$ (see above) and $\lim _{\alpha \rightarrow 1} e_{m i n}^{* *}=e_{m i n}^{*}$. Consequently, $\left.e_{m i n}^{* *}\right|_{\alpha<1}>$ $e_{\min }^{*}$ holds.

Proof of Proposition 4 (i) The proof of proposition 4 follows along the lines of the proof of proposition 3. Proposition 1, part (ii), implies that any tax-subsidy bundle $\left(\tau_{2}, s_{2}\right)$ with $s_{2}>0$ cannot be optimal, since an industry-friendly government prefers the equivalent tax-subsidy bundle $\left(\tau_{1}, 0\right)$, i.e. $W\left(\tau_{1}, 0, e_{\min }\right)>$ $W\left(\tau_{2}, s_{2}, e_{\text {min }}\right)$. Thus, the optimal policy mix is described by the first-order conditions $d W / d \tau=0$ and $d W / d e_{\min }=0$ (see (13) and (15)). ${ }^{20}$

Then, using $d W / d \tau=0$ and $d W / d e_{\min }=0$, comparative statics leads to

$$
\operatorname{sg} \frac{d \tau}{d \alpha}=\operatorname{sg}\left[\frac{d^{2} W}{d e_{\min } d \alpha} \frac{d^{2} W}{d \tau d e_{\min }}-\frac{d^{2} W}{d \tau d \alpha} \frac{d^{2} W}{d e_{\text {min }}^{2}}\right]
$$

\footnotetext{
${ }^{20}$ Again, it can be shown that the second order conditions are fulfilled for $\alpha$ sufficiently close to one. Cf. proof of proposition 3 .
} 
where $\frac{d^{2} W}{d \tau d e_{\min }}=-(\alpha-1) c \frac{[1-F(\widetilde{z})]^{2}+[F(\widetilde{z})]^{2}}{F^{\prime}(\widetilde{z})}-\frac{\partial^{2} D}{\partial E^{2}} Z_{L}^{a g g} Z_{H}^{a g g} \frac{d e_{H}}{d \tau}<0$ for $\alpha>1, \frac{d^{2} W}{d \tau d \alpha}=$ $c\left[\left(e_{H}-e_{L}\right) \frac{[1-F(\widetilde{z})]^{2}+[F(\widetilde{z})]^{2}}{F^{\prime}(\widetilde{z})}+(1+\tau) \frac{d e_{H}}{d \alpha} \frac{[F(\widetilde{z})]^{2}}{F^{\prime}(\widetilde{z})}\right]>0$, and $\frac{d^{2} W}{d e_{\min } d \alpha}<0$ (see proof of proposition 3, part (i)). These inequalities, together with $\frac{d^{2} W}{d e_{\min }^{2}}<0$ (see footnote 18 on second order conditions), imply that $d \tau^{* * *} / d \alpha>0$, as stated in part (i) of proposition 4.

Similarly, comparative statics yields

$$
\operatorname{sg} \frac{d e_{\min }^{* * *}}{d \alpha}=\operatorname{sg}\left[\frac{d^{2} W}{d \tau d e_{\min }} \frac{d^{2} W}{d \tau d \alpha}-\frac{d^{2} W}{d \tau^{2}} \frac{d^{2} W}{d e_{\min } d \alpha}\right]
$$

where $\frac{d^{2} W}{d \tau d e_{\text {min }}}<0$ for $\alpha>1, \frac{d^{2} W}{d \tau d \alpha}>0$, and $\frac{d^{2} W}{d e_{\min } d \alpha}<0$ (see above), together with $\frac{d^{2} W}{d \tau^{2}}<0$ (see, again, footnote 18 on second order conditions), imply that $d e_{\text {min }}^{* * *} / d \alpha<0$, as stated in part (i) of proposition 4 .

(ii) Any welfare-maximising tax-subsidy bundle $\left(\tau^{*}, s^{*}\right)$ can be replaced by an equivalent bundle $\left(\tau_{1}^{*}, 0\right)$ that also maximises welfare $W$ for $\alpha=1$ (see propositions 1 and 2). Also, $d \tau / d \alpha$ is a continuous function of $\alpha$ because, as can be shown, all terms of this derivative are continuous in $\alpha$. The optimal tax $\tau^{* * *}$ is thus a continuous function of $\alpha$, with $d \tau^{* * *} / d \alpha>0$ and $\lim _{\alpha \rightarrow 1} \tau^{* * *}=\tau_{1}^{*}$. Consequently, $\left.\tau^{* * *}\right|_{\alpha>1}>\tau_{1}^{*}$ holds. Then, $e_{H}\left(\tau^{* * *}, 0\right)>e_{H}\left(\tau_{1}^{*}, 0\right)=e_{H}\left(\tau^{*}, s^{*}\right)$, where the inequality sign follows from $d e_{H} / d \tau>0$ and the equals sign from definition 1 .

Similarly, $d e_{m i n} / d \alpha$ is a continuous function of $\alpha$. The optimal standard $e_{m i n}^{* * *}$ is thus a continuous function of $\alpha$, with $d e_{\min }^{* * *} / d \alpha<0$ and $\lim _{\alpha \rightarrow 1} e_{\min }^{* * *}=e_{\min }^{*}$. Consequently, $\left.e_{\min }^{* * *}\right|_{\alpha>1}<e_{\min }^{*}$ holds.

\section{References}

Arora, S., and Gangopadhyay, S. (1995), Toward a Theoretical Model of Voluntary Overcompliance, Journal of Economic Behavior and Organization 28, 289-309.

Austin, D., and Dinan, T. (2005), Clearing the Air: The Costs and Consequences of Higher CAFE Standards and Increased Gasoline Taxes, Journal of Environmental Economics and Management 50, 562-582.

Bansal, S. (2008), Choice and Design of Regulatory Instruments in the Presence of Green Consumers, Resource and Energy Economics 30, 345-368.

Bansal, S., and Gangopadhyay, S. (2003), Tax/Subsidy Policies in the Presence of Environmentally Aware Consumers, Journal of Environmental Economics and Management 45, 333-355. 
Council of the European Communities (1992), Council Directive 92/75/EEC, Official Journal of the European Communities No L 297, 16-19.

Crampes, C., and Hollander, A. (1995), Duopoly and Quality Standards, European Economic Review 39, 71-82.

Cremer, H., and Thisse, J.-F. (1994), Commodity Taxation in a Differentiated Oligopoly, International Economic Review 35, 613-633.

Cremer, H., and Thisse, J.-F. (1999), On the Taxation of Polluting Products in a Differentiated Industry, European Economic Review 43, 575-594.

Eriksson, C. (2004), Can Green Consumerism Replace Environmental Regulation? A Differentiated-Products Example, Resource and Energy Economics 26, 281293.

Espey, J. A., and Espey, M. (2004), Turning on the Lights: A Meta-Analysis of Residential Electricity Demand Elasticities, Journal of Agricultural and Applied Economics 36, 65-81.

Faberi, S., Esposito, R., Mebane, W., Scialdino, R., Stamminger, R. (2007), Preparartory Studies for Eco-Design Requirements of EuPs. Lot 14: Domestic Washing Machines and Dishwashers. Task 1 and 2, ISIS, ENEA, and University of Bonn.

Fraunhofer IZM (2007), Preparatory Studies for Eco-Design Requirements of EuPs. Lot 5: Televisions, Task 7, Fraunhofer Institute for Reliability and Microintegration, IZM, Berlin.

Gabszewicz, J. J., and Thisse, J.-F. (1979), Price Competition, Quality and Income Disparities, Journal of Economic Theory 20, 340-359.

Gillingham, K., Newell, R.G., Palmer, K. (2009), Energy Efficiency Economics and Policy, Annual Review of Resource Economics 1, 597-620.

Goodwin, P., Dargay, J., and Hanly, M. (2004), Elasticities of Road Traffic and Fuel Consumption with Respect to Price and Income: A Review, Transport Reviews 24, 275-292.

Hughes, J. E., Knittel, C. R., and Sperling, D. (2008), Evidence of a Shift in the Short-Run Price Elasticity of Gasoline Demand, Energy Journal 29, 113-134.

Lombardini-Riipinen, C. (2005), Optimal Tax Policy and Environmental Quality Competition, Environmental and Resource Economics 32, 317-336. 
Moraga-González, J. L., and Padrón-Fumero, N. (2002), Environmental Policy in a Green Market, Environmental and Resource Economics 22, 419-447.

Newell, R. G., Jaffe, A. B., and Stavins. R. N. (1999), The Induced Innovation Hypothesis and Energy-Saving Technological Change, Quarterly Journal of Economics 114, 941-975.

OECD (2006), The Political Economy of Environmentally Related Taxes, OECD, Paris.

OECD (2008), Household Behaviour and the Environment. Reviewing the Evidence, OECD, Paris.

Peltzman, S. (1976), Towards a More General Theory of Regulation, Journal of Law and Economics 19, 211-240.

Rauscher, M. (1997), International Trade, Factor Movements, and the Environment, Oxford: Oxford University Press.

Reiss, P. C., and White, M. W. (2005), Household Electricity Demand, Revisited, Review of Economic Studies 72, 853-883.

Rodriguez-Ibeas, R. (2007), Environmental Product Differentiation and Environmental Awareness, Environmental and Resource Economics 36, 237-254.

Ronnen, U. (1991), Minimum Quality Standard, Fixed Costs, and Competition, Rand Journal of Economics 22, 490-504.

Rosenfeld, A., McAuliffe, P., and Wilson, J. (2004), Energy Efficiency and Climate Change, in: C.J. Cutler et al. (eds.), Encyclopedia of Energy, Vol. 2, 373-382.

Shaked, A., and Sutton, J. (1982), Relaxing Price Competition Through Product Differentiation, Review of Economic Studies 49, 3-13.

Small, K. A., Van Dender, K. (2007), Fuel Efficiency and Motor Vehicle Travel: The Declining Rebound Effect, Energy Journal 28, 25-51. 


\section{CESifo Working Paper Series}

for full list see www.cesifo-group.org/wp

(address: Poschingerstr. 5, 81679 Munich, Germany, office@cesifo.de)

2921 Mariagiovanna Baccara, Allan Collard-Wexler, Leonardo Felli and Leeat Yariv, Gender and Racial Biases: Evidence from Child Adoption, January 2010

2922 Kurt R. Brekke, Roberto Cellini, Luigi Siciliani and Odd Rune Straume, Competition and Quality in Regulated Markets with Sluggish Demand, January 2010

2923 Stefan Bauernschuster, Oliver Falck and Niels Große, Can Competition Spoil Reciprocity? - A Laboratory Experiment, January 2010

2924 Jerome L. Stein, A Critique of the Literature on the US Financial Debt Crisis, January 2010

2925 Erkki Koskela and Jan König, Profit Sharing, Wage Formation and Flexible Outsourcing under Labor Market Imperfection, January 2010

2926 Gabriella Legrenzi and Costas Milas, Spend-and-Tax Adjustments and the Sustainability of the Government's Intertemporal Budget Constraint, January 2010

2927 Piero Gottardi, Jean Marc Tallon and Paolo Ghirardato, Flexible Contracts, January 2010

2928 Gebhard Kirchgässner and Jürgen Wolters, The Role of Monetary Aggregates in the Policy Analysis of the Swiss National Bank, January 2010

2929 J. Trent Alexander, Michael Davern and Betsey Stevenson, Inaccurate Age and Sex Data in the Census PUMS Files: Evidence and Implications, January 2010

2930 Stefan Krasa and Mattias K. Polborn, Competition between Specialized Candidates, January 2010

2931 Yin-Wong Cheung and Xingwang Qian, Capital Flight: China's Experience, January 2010

2932 Thomas Hemmelgarn and Gaetan Nicodeme, The 2008 Financial Crisis and Taxation Policy, January 2010

2933 Marco Faravelli, Oliver Kirchkamp and Helmut Rainer, Social Welfare versus Inequality Concerns in an Incomplete Contract Experiment, January 2010

2934 Mohamed El Hedi Arouri and Christophe Rault, Oil Prices and Stock Markets: What Drives what in the Gulf Corporation Council Countries?, January 2010

2935 Wolfgang Lechthaler, Christian Merkl and Dennis J. Snower, Monetary Persistence and the Labor Market: A New Perspective, January 2010 
2936 Klaus Abberger and Wolfgang Nierhaus, Markov-Switching and the Ifo Business Climate: The Ifo Business Cycle Traffic Lights, January 2010

2937 Mark Armstrong and Steffen Huck, Behavioral Economics as Applied to Firms: A Primer, February 2010

2938 Guglielmo Maria Caporale and Alessandro Girardi, Price Formation on the EuroMTS Platform, February 2010

2939 Hans Gersbach, Democratic Provision of Divisible Public Goods, February 2010

2940 Adam Isen and Betsey Stevenson, Women's Education and Family Behavior: Trends in Marriage, Divorce and Fertility, February 2010

2941 Peter Debaere, Holger Görg and Horst Raff, Greasing the Wheels of International Commerce: How Services Facilitate Firms' International Sourcing, February 2010

2942 Emanuele Forlani, Competition in the Service Sector and the Performances of Manufacturing Firms: Does Liberalization Matter?, February 2010

2943 James M. Malcomson, Do Managers with Limited Liability Take More Risky Decisions? An Information Acquisition Model, February 2010

2944 Florian Englmaier and Steve Leider, Gift Exchange in the Lab - It is not (only) how much you give ..., February 2010

2945 Andrea Bassanini and Giorgio Brunello, Barriers to Entry, Deregulation and Workplace Training: A Theoretical Model with Evidence from Europe, February 2010

2946 Jan-Emmanuel De Neve, James H. Fowler and Bruno S. Frey, Genes, Economics, and Happiness, February 2010

2947 Camille Cornand and Frank Heinemann, Measuring Agents' Reaction to Private and Public Information in Games with Strategic Complementarities, February 2010

2948 Roel Beetsma and Massimo Giuliodori, Discretionary Fiscal Policy: Review and Estimates for the EU, February 2010

2949 Agnieszka Markiewicz, Monetary Policy, Model Uncertainty and Exchange Rate Volatility, February 2010

2950 Hans Dewachter and Leonardo Iania, An Extended Macro-Finance Model with Financial Factors, February 2010

2951 Helmuth Cremer, Philippe De Donder and Pierre Pestieau, Education and Social Mobility, February 2010

2952 Zuzana Brixiová and Balázs Égert, Modeling Institutions, Start-Ups and Productivity during Transition, February 2010 
2953 Roland Strausz, The Political Economy of Regulatory Risk, February 2010

2954 Sanjay Jain, Sumon Majumdar and Sharun W. Mukand, Workers without Borders? Culture, Migration and the Political Limits to Globalization, February 2010

2955 Andreas Irmen, Steady-State Growth and the Elasticity of Substitution, February 2010

2956 Bengt-Arne Wickström, The Optimal Babel - An Economic Framework for the Analysis of Dynamic Language Rights, February 2010

2957 Stefan Bauernschuster and Helmut Rainer, From Politics to the Family: How Sex-Role Attitudes Keep on Diverging in Reunified Germany, February 2010

2958 Patricia Funk and Christina Gathmann, How do Electoral Systems Affect Fiscal Policy? Evidence from State and Local Governments, 1890 to 2005, February 2010

2959 Betsey Stevenson, Beyond the Classroom: Using Title IX to Measure the Return to High School Sports, February 2010

2960 R. Quentin Grafton, Tom Kompas and Ngo Van Long, Biofuels Subsidies and the Green Paradox, February 2010

2961 Oliver Falck, Stephan Heblich, Alfred Lameli and Jens Suedekum, Dialects, Cultural Identity, and Economic Exchange, February 2010

2962 Bård Harstad, The Dynamics of Climate Agreements, February 2010

2963 Frederick van der Ploeg and Cees Withagen, Is There Really a Green Paradox?, February 2010

2964 Ingo Vogelsang, Incentive Regulation, Investments and Technological Change, February 2010

2965 Jan C. van Ours and Lenny Stoeldraijer, Age, Wage and Productivity, February 2010

2966 Michael Hoel, Climate Change and Carbon Tax Expectations, February 2010

2967 Tommaso Nannicini and Roberto Ricciuti, Autocratic Transitions and Growth, February 2010

2968 Sebastian Brauer and Frank Westermann, A Note on the Time Series Measure of Conservatism, February 2010

2969 Wolfram F. Richter, Efficient Education Policy - A Second-Order Elasticity Rule, February 2010

2970 Tomer Blumkin, Yoram Margalioth and Efraim Sadka, Taxing Children: The Redistributive Role of Child Benefits - Revisited, February 2010 
2971 Chang Woon Nam and Georg Wamser, Application of Regionally Varying Additionality Degrees in the Practice of EU Cohesion Policy, February 2010

2972 Ali Bayar, Frédéric Dramais, Cristina Mohora, Masudi Opese and Bram Smeets, Modeling Russia for Climate Change Issues, February 2010

2973 Magnus Söderberg, Informal Benchmarks as a Source of Regulatory Threat in Unregulated Utility Sectors, March 2010

2974 Piotr Wdowiński and Marta Malecka, Asymmetry in Volatility: A Comparison of Developed and Transition Stock Markets, March 2010

2975 Frans van Winden, Michal Krawczyk and Astrid Hopfensitz, Investment, Resolution of Risk, and the Role of Affect, March 2010

2976 Hyun-Ju Koh and Nadine Riedel, Do Governments Tax Agglomeration Rents?, March 2010

2977 Johann K. Brunner and Susanne Pech, Optimum Taxation of Bequests in a Model with Initial Wealth, March 2010

2978 Guglielmo Maria Caporale and Nicola Spagnolo, Stock Market Integration between three CEECs, Russia and the UK, March 2010

2979 Florian Englmaier, Ales Filipi and Ravi Singh, Incentives, Reputation and the Allocation of Authority, March 2010

2980 Konstantinos Angelopoulos, George Economides and Apostolis Philippopoulos, What is the Best Environmental Policy? Taxes, Permits and Rules under Economic and Environmental Uncertainty, March 2010

2981 Frederick van der Ploeg, Rapacious Resource Depletion, Excessive Investment and Insecure Property Rights, March 2010

2982 Wolfram F. Richter and Christoph Braun, Efficient Subsidization of Human Capital Accumulation with Overlapping Generations and Endogenous Growth, March 2010

2983 Francesco Cinnirella, Marc Piopiunik and Joachim Winter, Why Does Height Matter for Educational Attainment? Evidence from German Pre-Teen Children, March 2010

2984 Bernard Van Praag, Well-being Inequality and Reference Groups - An Agenda for New Research, March 2010

2985 Francesca Barion, Raffaele Miniaci, Paolo M. Panteghini and Maria Laura Parisi, Profit Shifting by Debt Financing in Europe, March 2010

2986 Alexander Haupt and Magdalena Stadejek, The Choice of Environmental Policy Instruments: Energy Efficiency and Redistribution, March 2010 